\title{
"Como se le habla a un hermano":" la solidaridad hacia Cuba y Vietnam en la Nueva Canción Chilena (1967-1973)
}

\author{
"As you Speak to a Brother": \\ Solidarity towards Cuba and Vietnam \\ in the Chilean New Song (1967-1973)
}

\author{
Eileen Karmy* \\ (D) https://orcid.org/0000-0003-4174-9694 \\ University of Glasgow, Escocia \\ ekarmyb@gmail.com
}

\section{Natália Ayo Schmiedecke** \\ (D) https://orcid.org/0000-0002-6515-5965 \\ Universidad Estatal de Campinas, Brasil \\ nati.ayo@gmail.com}

Resumen: La Nueva Canción Chilena (NCCh) contribuyó a expresar la solidaridad de la izquierda chilena hacia las revoluciones cubana y vietnamita antes

${ }^{1}$ Referencia a la canción “A Cuba”, de Víctor Jara, que comentamos al final de la segunda sección del artículo.

* Doctora en Musicología por la Universidad de Glasgow, Escocia.

** Doctora en Historia por la Universidad Estatal Paulista "Júlio de Mesquita Filho", Brasil. Posdoctoranda en el Departamento de Historia de la Universidad Estatal de Campinas, Brasil. Becaria de la FAPEsP (proceso 2018/00325-0).

cómo citar: Karmy, E. y Schmiedecke, N. A. (2020). “Como se le habla a un hermano”: la solidaridad hacia Cuba y Vietnam en la Nueva Canción Chilena (1967-1973). Secuencia (108), e1834. Dor: https://doi. org/10.18234/secuencia.v0i108.1834 
y durante la Unidad Popular (1970-1973). Por la particularidad del caso chileno y su "vía pacífica" al socialismo, el apoyo a estas luchas revolucionarias no estuvo exento de conflictos. Aquí analizamos cómo estos artistas expresaron su solidaridad hacia ambas revoluciones y cómo sortearon o profundizaron dichos conflictos. Presentamos dos hallazgos principales. El primero destaca la relevancia de la NCch en la denuncia del imperialismo estadunidense y como expresión de solidaridad Sur-Sur. El segundo documenta el uso de géneros, instrumentos e intertextualidad para apoyar a dichos pueblos y validar la "vía chilena". El análisis de este repertorio bajo las nociones de solidaridad Sur-Sur es novedoso, puesto que permite develar las estrategias usadas tanto para expresar solidaridad como para insertar la "vía chilena" en el contexto de la guerra fría.

Palabras clave: Nueva Canción Chilena; Unidad Popular; solidaridad Sur-Sur; Cuba; Vietnam.

Abstract: The Chilean New Song contributed to express solidarity with the $\mathrm{Cu}-$ ban and Vietnamese revolutions before and during the Popular Unity government (1970-1973). Due to the particularity of the Chilean case and its "peaceful way to socialism", this support was not without controversy. This article analyzes how New Song artists expressed their solidarity to both revolutions and how they either bypassed or deepened such conflicts. We present two findings. The first highlights the relevance of Chilean New Song in denouncing the American imperialism while showing solidarity with others. The second sheds light on the use of genres, instruments and intertextuality to support Cuba and Vietnam but also to validate the "Chilean way". Analyzing this repertoire through the notion of South-South solidarity is innovative since it unveils the strategies that musicians used to express their solidarity while integrating the "Chilean way" in the international context of the cold war.

Key words: Chilean New Song; Popular Unity; South-South solidarity; Cuba; Vietnam.

Recibido: 29 de febrero de 2020 Aceptado: 26 de junio de 2020 Publicado: 1 de diciembre de 2020 


\section{INTRODUCCIÓN}

$\mathrm{L}$ os años sesenta y setenta latinoamericanos tuvieron como marca la expectativa revolucionaria, cuyo referente era un escenario internacional de movimientos de protesta al orden establecido. Acontecimientos como la revolución cubana (1959), la descolonización africana (1956-1974), la guerra de Vietnam (1955-1975) y el movimiento por los derechos civiles en Estados Unidos (1954-1980) sugerían a los contemporáneos que el mundo estaba por cambiar radicalmente.

En este contexto, muchos artistas expresaron su compromiso político. En el campo musical, proliferaron movimientos a lo largo del continente que reivindicaron la canción política como arma de lucha-caso, entre otros, de la Nueva Canción Chilena, el Nuevo Cancionero Argentino, la Nueva Canción Uruguaya y la Nueva Trova Cubana-. Cercanos a la izquierda política, estos movimientos alzaron la bandera del antiimperialismo y manifestaron apoyo a procesos revolucionarios desatados en diferentes partes del globo.

En este artículo examinaremos la relación que los músicos de la Nueva Canción Chilena (NCch) establecieron con procesos de lucha armada en los años previos a y durante el gobierno de la Unidad Popular (UP). A diferencia de la mayoría de los movimientos revolucionarios que se desarrollaron en el llamado Tercer Mundo en la segunda mitad del siglo veinte, las principales organizaciones políticas de la izquierda chilena optaron por la vía pacífica o no armada de acceso al poder. Así, formaron coaliciones para disputar elecciones y lograron elegir al presidente socialista Salvador Allende en 1970. Su programa de gobierno, conocido como "vía chilena al socialismo", proponía la implementación gradual del socialismo en Chile, respetando la institucionalidad democrática. La "experiencia chilena" fue interrumpida violentamente por el golpe de Estado del 11 de septiembre de 1973, que condujo a la dictadura cívico-militar liderada por el general Augusto Pinochet.

Aunque la estrategia "gradualista" o "sistémica" se impuso en la práctica, esta generó mucha polémica al interior de la izquierda desde que la "vía chilena" empezó a gestarse, a mediados de los años cincuenta. Durante el gobierno de Allende se observaron tensiones, debates y diferencias entre polos interpretativos, no sólo entre la UP y las organizaciones de izquierda externas a la coalición, sino también en su propio seno. Otras experiencias revolucionarias influenciaron estos embates, las cuales fueron tomadas o como modelos a seguir, o bien como procesos incompatibles con la realidad nacional (Casals, 2010). 
Desarrollaremos esta problemática examinando cómo la Ncch incorporó a su repertorio discos y canciones de solidaridad con las revoluciones cubana y vietnamita. Exploraremos de qué modo se abordaron estas temáticas, tanto en términos musicales como líricos, textuales e intertextuales. Al mismo tiempo, revisaremos en qué medida la incorporación de canciones de solidaridad con Cuba y Vietnam conflictuó con la vía chilena al socialismo, y cómo los artistas de la NCch sortearon o profundizaron estos conflictos.

Para ello consultamos diferentes tipos de fuentes, incluyendo canciones, discos, documentales, materiales publicados en prensa y relatos autobiográficos. Buscamos identificar alusiones explícitas e implícitas a Cuba y Vietnam en el repertorio grabado por músicos representativos de la NCch antes y durante la Up. De este repertorio seleccionamos algunos casos musicales para analizar en detalle. Incluimos indistintamente creaciones originales como versiones ${ }^{2}$ de canciones anteriores; temas instrumentales y cantados; obras de agrupaciones y solistas. El repertorio seleccionado corresponde a canciones u obras de largo aliento que, tanto por sus textos como por sus características musicales (género, instrumentación, arreglos), representan las problemáticas discutidas a lo largo del artículo. Si bien algunas de estas piezas musicales fueron más conocidas que otras, todas fueron grabadas y difundidas en los años en los que se enmarca este estudio, siendo parte también de la circulación y recepción musical de la época.

Con este artículo buscamos contribuir al creciente campo de investigación sobre la historia cultural de la guerra fría, y en específico, desarrollar un aspecto sobre la Ncch que ha sido poco estudiado, como vehículo creador de subjetividades revolucionarias en el contexto de la solidaridad Sur-Sur. Este trabajo colinda con distintos subcampos de la investigación histórica y musical, por lo que usaremos una perspectiva de análisis hermenéutica tanto en lo teórico como en lo metodológico. En el marco de la historia cultural, interesada por las relaciones entre prácticas y representaciones (Chartier, 2002), analizaremos el modo en que el proyecto político de la UP se posicionó y actuó en torno a las problemáticas internacionales contemporáneas. Recurriremos a las herramientas del análisis intertextual musical para entender las conexiones entre las luchas de Vietnam, Cuba y Chile, y explicar cómo

\footnotetext{
${ }^{2}$ Utilizamos el concepto de versión como "una actualización en forma de nueva grabación o performance de una canción o tema instrumental que ya ha sido interpretado y/o grabado con anterioridad" (López Cano, 2011, p. 3).
} 
los músicos de la Ncch situaron su propio compromiso revolucionario en un ámbito internacionalista.

Nuestro argumento es que la actitud de los músicos chilenos constituye un caso de solidaridad transnacional Sur-Sur en el contexto de la guerra fría. Como señala Featherstone (2012), la solidaridad -definida como una "relación forjada a través de la lucha política que busca desafiar formas de opresión" (p. 5) - ha sido históricamente una práctica central de los movimientos sociales de izquierda. El autor plantea que las relaciones de solidaridad son transformadoras y pueden realizarse "desde abajo", sin necesariamente enmarcarse en un contexto nacional. Considera además la necesidad de pensar la solidaridad en términos políticos, ya que ésta permite construir relaciones entre diferentes lugares, grupos sociales y activistas, ya sea consolidando identidades y relaciones de poder existentes, o bien creando nuevas formas de relacionarse. Identifica también una importante relación entre rechazo y solidaridad, ya que esta "puede forjarse a través de antagonismos" (p. 7) y, a la vez, modelar disputas políticas. Como veremos, la solidaridad expresada por la Ncch con las luchas cubana y vietnamita tenía como eje la oposición a un enemigo común: el imperialismo estadunidense. En un contexto en que los temas del anticapitalismo y el internacionalismo estaban conectados, los movimientos revolucionarios desarrollados en diferentes partes del mundo fueron percibidos como "comunidades superpuestas de resistencia" (p. 8).

La relevancia de estudiar la producción artístico-cultural solidaria en el contexto latinoamericano ha sido subrayada por Stiles Mor y Suescun Pozas (2018, pp. 3-7), quienes afirman la capacidad que tiene el arte de enmarcar cuestiones sociales y difundir representaciones identitarias, generando empatía. De acuerdo con las autoras, la solidaridad supone empatía, la cual constituye una forma de acción política y social. Black (2018) desarrolla el mismo argumento para el caso de la música, la cual puede ser utilizada "para transmitir una identidad común y salvar diferencias culturales, para expresar un sentido de solidaridad con personas que comparten valores similares" (p. 121). La autora señala que la canción protesta (también llamada de compromiso social, comprometida o revolucionaria) de los años sesenta ha sido un "componente crucial de lucha por igualdad social y liberación del Tercer Mundo a lo largo del hemisferio occidental y más allá” (p. 122).

3 Todas las traducciones de textos publicados originalmente en otros idiomas son de nuestra autoría. 
A diferencia de la solidaridad Sur-Norte, que ha sido criticada por reforzar nociones de diferencia y justificar relaciones de poder asimétricas, las relaciones Sur-Sur, aunque no esquivan completamente el problema de la otredad, ofrecen la posibilidad de relaciones recíprocas (Stiles Mor y Suescun Pozas, 2018, p. 5). Cuando hablamos de "sur", tenemos presentes dos conceptualizaciones complementarias. La primera es heredera del Brandt Report (Independent Commission on International Development Issues, 1980) y se refiere a los países menos desarrollados económicamente, que en general se ubican en el hemisferio sur del planeta. Más recientemente, el reconocimiento de que las relaciones de desigualdad no se dan solamente entre países, sino también al interior de los mismos, llevó a la formulación de la noción de "Sur global". Si bien este término ha sido comúnmente usado como una alternativa del concepto de "Tercer mundo", en los últimos años, ha comenzado a ser entendido como una categoría crítica que encapsula un sentido transnacional para referirse a espacios y personas subyugados por el capitalismo global (Mahler, 2018, p. 6). Por lo tanto, el "sur" supone la "coexistencia de asimetrías de poder intra, inter y transnacionales y una simultánea "posibilidad de solidaridad' a través de fuerzas políticas y sociales que resisten y buscan transformar estas desigualdades" (Muhr y Azevedo, 2019, p. 4).

Siguiendo a Mahler (2018), la noción de "Sur global" tiene como antecedente el discurso del Tricontinentalismo de los años sesenta. ${ }^{4}$ Este es entendido como un discurso referido a "una comunidad afectiva de solidaridad que trasciende la geografía nacional y regional, y cuyas afinidades no se basan ni en el lugar, ni el idioma, ni la sangre" (Mahler, 2018, p. 10). De este modo, este discurso mueve la noción de color del significado racial al político, tomándolo como base para articular una crítica al sistema global del imperialismo a través de la denuncia de la desigualdad. Como veremos, el argumento de que el Tricontinentalismo constituyó la infraestructura primaria para la producción cultural de la izquierda durante la guerra fría (p. 8), se confirma en el caso de la NCch. Al igual que con los materiales producidos en el marco de la Tricontinental (p. 11), encontramos también convergencias y tensiones entre la Ncch y su solidaridad hacia Cuba y Vietnam.

${ }^{4}$ El Tricontinentalismo es concebido como "un discurso transnacional que comienza a tomar forma antes de la Conferencia Tricontinental [1966], que circula fuera de los materiales producidos por la propia Tricontinental, que reemplaza al Estado cubano y cuya influencia se puede ver en los movimientos sociales transnacionales contemporáneos" (Mahler, 2018, p. 9). 
En este artículo desarrollaremos el argumento de que los músicos de la NCch expresaron su solidaridad hacia Cuba y Vietnam en sus luchas revolucionarias no necesariamente por considerarlos modelos a seguir, sino como pueblos hermanos, en situaciones similares de explotación y dominación imperialista. Así, sus canciones contribuirán, por una parte, a visibilizar la importancia de apoyar explícitamente los procesos revolucionarios de Cuba y Vietnam y, por otra, a insertar a la vía chilena al socialismo dentro del amplio panorama revolucionario del llamado Tercer Mundo en el marco de la guerra fría.

La historiografía sobre la NCch ha tendido a enfocarse en el contexto nacional, especialmente en la relación entre los músicos y el gobierno de la UP. En los últimos años han salido a la luz algunos estudios que buscan dar cuenta de su dimensión internacional, ya sea examinando las conexiones con otros movimientos latinoamericanos de la canción comprometida (Gomes, 2015 y 2018) o su circulación internacional (Rodríguez 2015, 2016 y 2017). Estos trabajos incluyen secciones dedicadas a las relaciones Chile-Cuba y hacen hincapié en las asociaciones entre músicos de ambos países. La solidaridad de los músicos chilenos con la lucha vietnamita ha sido estudiada por Gómez (2014), quien enumera las obras musicales sobre este tema, tanto doctas como populares, creadas entre 1965 y 1975, propone una forma de clasificar a las canciones según sus temáticas, y subraya la variedad de formas musicales utilizadas. Aunque este es un trabajo valioso y original, el autor no profundiza en el análisis de las canciones ni cubre algunos músicos relevantes de la NCch, como el dúo Amerindios. Por otra parte, Gómez concluye que hay un denominador común en la producción discográfica estudiada: la doble referencia a Vietnam y Cuba. Al enfocarnos precisamente en este tema, e incluir a músicos que han sido previamente pasados por alto en este tipo de investigaciones, buscamos aportar elementos para la continuidad y desarrollo de esta nueva línea de estudio de la NCch.

El artículo está organizado en tres secciones. La primera aborda el surgimiento y desarrollo de la Nueva Canción Chilena, señalando su posicionamiento político y su tendencia a exceder la identidad nacional. La segunda examina los homenajes musicales a Cuba y Vietnam hechos por músicos chilenos antes de que la up fuera gobierno. Finalmente, se presenta el análisis de las canciones que rinden tributo a Cuba y Vietnam estrenadas durante los años de la UP y se discuten las estrategias y adaptaciones que los músicos chilenos usaron para evitar conflictos con la "vía chilena al socialismo". 


\section{"EL CANTAR TIENE SENTIDO": ${ }^{5}$ LA NUEVA CANCIÓN CHILENA}

Inspirados en el Nuevo Cancionero Argentino, en la folclorista, música y artista plástica Violeta Parra, y en los conjuntos de música andina con los que mantuvieron contacto durante su estadía en París, los hermanos Ángel e Isabel Parra inauguraron la Peña de Los Parra en Santiago de Chile en 1965. Esta Peña fue concebida como una especie de cooperativa de artistas y tuvo en su elenco inicial, además de los hermanos Parra, a Rolando Alarcón y Patricio Manns. En 1966, el músico y artista de teatro Víctor Jara se integró también a este grupo. El repertorio de estos artistas se compuso de canciones que promovían una relectura del folclor, introduciendo temáticas y sonoridades que se apartaban de las prácticas tradicionales y conformaban un discurso latinoamericanista y contestatario.

En los años siguientes, las canciones de los integrantes de la Peña, así como de otros solistas y conjuntos que seguirían sus pasos, fueron adquiriendo formas políticas más explícitas. Ya no se cantaría acerca de los bellos paisajes del campo como habían hecho los folcloristas más tradicionales, sino que de las contradicciones del latifundio latinoamericano y de la explotación patrón/campesino. Este mismo interés se extrapolaría a otras regiones de Latinoamérica, donde la explotación y la injusticia eran comunes en la minería, la industria, e incluso en los centros urbanos. Sonoramente, este cambio de foco se expresó en la inclusión de instrumentos musicales que hasta el momento no eran conocidos masivamente en Chile, como el charango, la quena y las zampoñas. Al mismo tiempo, las canciones comenzaron a sonar en ritmos folclóricos de la región andina, compartida por Chile, Perú, Bolivia y Argentina, tales como el huayño y el taquirari. De este modo, se hacía visible y audible una tradición cultural que había sido negada históricamente de la identidad chilena, especialmente después de la guerra del Pacífico. ${ }^{6}$ Esta bús-

${ }^{5}$ Referencia al disco del mismo nombre editado bajo el sello Asfona en 1971 en el que grabaron Isabel Parra, Rolando Alarcón, Ángel Parra, Tiemponuevo e Inti-Illimani. La canción que da nombre al disco proviene del folclor venezolano y fue originalmente grabada por Isabel Parra en el LP La Peña de los Parra, vol. 1, en 1969.

${ }^{6}$ Con la guerra del Pacífico o guerra contra la Confederación Perú-Boliviana, que tuvo lugar entre 1879 y 1884, la identidad chilena buscó redefinirse en oposición a la identidad andina, asociada con los países de Perú y Bolivia. Como señala Pedemonte (2008), esta guerra fue utilizada para unir a chilenos y chilenas en una causa común, después de importantes crisis 
queda por incluir la región andina y hacerla parte de la identidad nacional era una negación a ese "blanqueamiento" histórico y una señal de unidad e identidad latinoamericana más que nacional.

Entre los diferentes factores que contribuirían al surgimiento de la canción comprometida en Chile, podemos destacar el clima de fuertes antagonismos que marcó el final del mandato del demócrata cristiano Eduardo Frei (1964-1970); el movimiento por la Reforma Universitaria (1967-1973), que promovió la articulación entre música, juventud y política; y la realización en Cuba del Encuentro de la Canción Protesta, entre el 29 de julio y el 10 de agosto de $1967 .^{7}$ Este último fue organizado por la Casa de las Américas y se desarrolló en simultáneo a la Primera Conferencia de Solidaridad de los Pueblos de América Latina que oficializó la creación de la Organización Latinoamericana de Solidaridad (OLAS), definida por Calvo (2018) como "la culminación de la orientación revolucionaria del castrismo" o, en las palabras de Rey, reproducidas por la misma autora, como "la vía para la constitución de una nueva internacional dominada por La Habana” (p. 159).

En el Encuentro se reunieron artistas de distintos países que, entre otras actividades, participaron en mesas redondas, realizaron presentaciones musicales en variados escenarios, establecieron redes de contacto y planificaron proyectos conjuntos. En una reseña para la revista Casa de las Américas, el periodista José Ossorio (1967) destacó que las canciones interpretadas durante el evento "se referían a la lucha de liberación, a la denuncia social y política, a la guerra de Viet Nam, a la discriminación racial" y adoptaban formas diversas, que podrían ser "folklóricas, populares o formas musicales modernas" (p. 140). Según el autor, los participantes discutieron respecto al concepto de "canción protesta" y sugirieron nombres alternativos. Sin embargo, este desacuerdo no impidió un consenso "en cuanto a los fines que la canción protesta persigue" (p. 141), los cuales se explicitaron en la resolución firmada al final del Encuentro:

Los trabajadores de la canción de protesta deben tener conciencia de que la canción, por su particular naturaleza, posee una enorme fuerza de comunica-

durante la vida independiente del país (pp. 119-120) mediante la producción de símbolos nacionales que enaltecían el patriotismo (pp. 137-153).

${ }^{7}$ Del Encuentro resultó la grabación de un álbum, compuesto por dos Long Plays (LPs) que reunían obras de varios participantes, y la creación del Centro de la Canción Protesta. 
ción con las masas [...] En consecuencia, la canción debe ser un arma al servicio de los pueblos, no un producto de consumo utilizado por el capitalismo para enajenarlos. [...] La tarea de los trabajadores de la canción de protesta debe desarrollarse a partir de una toma de posición definida junto a su pueblo frente a los problemas de la sociedad en que vive. (pp. 143-144)

Así, los participantes reivindicaron el derecho y el deber del músico a utilizar su oficio como medio de intervención en la sociedad y defendieron el uso de la canción para transmitir mensajes políticos. Siguiendo el principio de que el artista debería tomar una posición definida frente a las problemáticas de su tiempo, el texto también denunciaba los "crímenes del imperialismo contra el pueblo de Viet Nam", exigiendo el fin a los bombardeos en el norte del país y la retirada de las tropas estadunidenses del sur. Al mismo tiempo, apoyaba a la "creciente lucha del pueblo negro de los Estados Unidos contra todas las formas de discriminación y explotación" y a la "lucha proletaria y estudiantil que en los países capitalistas se libra contra la explotación patronal". Finalmente, exaltaba la revolución cubana, "que ha señalado el verdadero camino que deben tomar los pueblos de Asia, África y América para liberarse" (p. 144). De este modo, se entendió el antiimperialismo como una causa común a todos los pueblos que buscaban su soberanía y Cuba surgió como ejemplo y guía a las revoluciones del mundo.

Influenciados por las definiciones concebidas en el Encuentro de la Canción Protesta, como veremos más adelante, e inmersos en un ambiente de creciente polarización política, un conjunto de músicos declaró su apoyo a la candidatura presidencial de Salvador Allende en 1970. Entre otros, Víctor Jara, Isabel y Ángel Parra, Rolando Alarcón, Patricio Manns, Sergio Ortega, así como los integrantes de los conjuntos Quilapayún, Inti-Illimani, Aparcoa y Tiemponuevo participaron en distintas actividades de la campaña electoral de la UP y grabaron canciones en apoyo al candidato de la izquierda. ${ }^{8}$ En este contexto, el término "Nueva Canción Chilena" pasó a ser utilizado para referirse al movimiento de la canción comprometida chilena (Schmiedecke, 2014a). Durante los siguientes tres años, los músicos de la Ncch direccionaron su trabajo a la defensa del gobierno electo y algunos llegaron a ser nom-

${ }^{8}$ Por ejemplo, "En septiembre cantará el gallo", de Isabel Parra; "Unidad Popular", de Ángel Parra, y "Venceremos", marcha compuesta por Sergio Ortega e interpretada por Quilapayún. 
brados "embajadores culturales" por Allende, lo que contribuyó para la identificación entre el movimiento y la up (Schmiedecke, 2017, pp. 53-55).

Diversos estudios de la NCch han destacado no sólo el compromiso político de los músicos, sino también han desarrollado críticas a este movimiento, develando ciertos conflictos o contradicciones al interior del mismo. Sin querer ahondar en ello, pues no es el objetivo de este trabajo, consideramos importante mencionar la problemática en relación con el tema de género. ${ }^{9}$ No sólo la gran mayoría de los músicos de la Ncch pertenecen al género masculino, sino que también cantaban al ideario revolucionario del "hombre nuevo". Esta problemática la retomaremos al analizar los significados intertextuales de parte del repertorio tratado aquí. Es relevante que casi todas las figuras cubanas o vietnamitas a las que rinde tributo el repertorio son hombres. Y, como analizaremos en las canciones escogidas, en muchos casos su masculinidad es exaltada como una virtud revolucionaria, tanto en el texto poético como en el modo interpretativo. En otros, se presenta excepcionalmente a las mujeres como sujetos activos, pero para ironizar.

En los siguientes apartados examinaremos el repertorio internacionalista de la Ncch antes y después de 1970. Veremos que, aunque los músicos promoverán las identidades latinoamericana y tercermundista, y buscarán establecer lazos con procesos revolucionarios desplegados por la vía armada, contribuirán también a diferenciar estos procesos de la vía chilena.

\section{"UN SON REVOLUCIONARIO":"10 ANTES DE LA UP}

Antes de que la Unidad Popular llegara al gobierno, ya los músicos de la Ncch realizaban homenajes a la revolución cubana y a la resistencia vietnamita en sus grabaciones y conciertos. Estas canciones no son sólo muestra de la solidaridad internacional que Chile estableció con luchas revolucionarias de distintos "sures", sino que también ayudaron a que el pueblo chileno se identificara con estas otras luchas, contribuyendo a instalar la solidaridad Sur-Sur en la sociedad chilena.

9 Sobre la problemática de género en la Nueva Canción Chilena, véase Rodríguez (2011); Vila (2014); Karmy (2014a); Party (2019).

${ }^{10}$ Referencia a la canción “A Cuba”, de Víctor Jara, comentada más adelante. 
Ya en 1967, el disco Canción Protesta, grabado en Cuba en el marco del encuentro homónimo contó con canciones de Rolando Alarcón, Isabel y Ángel Parra, que representaron a Chile en dicho evento. Dos años más tarde, la Casa de las Américas lanzaría el disco Hasta la victoria siempre, Ché querido. Aquí, el segundo tema editado fue una versión de Víctor Jara y Quilapayún de la canción que el mexicano Rubén Ortiz compuso tras la muerte del guerrillero, "Zamba del Che”. En el mismo disco grabó también Quilapayún "Canción fúnebre para el Che Guevara”, escrita por el músico chileno Juan Capra. "Zamba del Che" fue incluida en el LP Pongo en tus manos abiertas... (Víctor Jara, 1969), mientras que "Canción fúnebre para el Che Guevara" había sido grabada previamente en X Viet-nam (Quilapayún, 1968).

Es interesante cómo estas canciones utilizan recursos no sólo textuales y explícitos, sino que también intertextuales e interpretativos para rendirle un homenaje al guerrillero argentino. En ambas canciones se emplearon instrumentos y géneros musicales popularizados por la NCch: en la primera, un bombo legüero; en la segunda, una quena y un charango, además del bombo. En el caso de "Zamba del Che", se utiliza la zamba, el género típico del norte de Argentina, para cantarle a Ernesto "Che" Guevara. La versión de Víctor Jara no sólo mantiene el género sino que enfatiza su estilo dramático con el uso de la guitarra, especialmente al agregarle algunos interludios. El músico chileno también hace cambios en la letra de la canción:

\section{Explotan al campesino \\ al minero y al obrero, \\ cuánto dolor en su vida \\ hambre miseria y sudor.}

Versión de Ortiz
Explotan al campesino
al minero y al obrero,
cuánto dolor su destino,
hambre miseria y dolor.

Versión de Jara

Si bien sutil, el reemplazo de estos versos en la cuarta estrofa enfatiza la situación de explotación de los trabajadores latinoamericanos (campesinos, mineros y obreros). Por una parte, la versión de Jara da cuenta que, diferente a como cantaba Ortiz, el dolor no constituiría una condición particular de la vida del campesino, el minero y el obrero, sino que de su destino en tanto trabajadores explotados. La palabra "destino" tiene un sentido más determinista que el de "vida", y que sería un destino compartido por la clase trabajadora más allá de una característica de la vida de cada trabajador. Junto a esto, el reemplazo de "sudor" por "dolor" hace explícito el sufrimiento de las clases 
oprimidas; ya no se trata solamente del "sudor" por el esfuerzo que implica el trabajo, sino que también el "dolor" de la explotación. Finalmente, Víctor Jara canta "liberar a nuestro pueblo del dominio explotador" (en singular), mientras que Ortiz lo hace en plural ("nuestros pueblos"). Este cambio puede tener dos connotaciones. Por una parte, que para hablar del pueblo latinoamericano no es necesario hablar en plural, puesto que se entendía como a un solo pueblo, unido en una misma lucha. Por otra, podría interpretarse también en el contexto de la construcción de la "vía chilena al socialismo", en el Chile pre-up, del que emerge esta versión, sugiriendo que ahora será el pueblo chileno el que se liberará del dominio explotador.

Estas canciones son representativas de la creciente politización del repertorio de los músicos que integraban la Ncch. Según analiza Gomes (2015, pp. 100-116), las concepciones defendidas en el Encuentro de la Canción Protesta se dejaron oír en discos de Ángel Parra, Rolando Alarcón y Víctor Jara, lanzados entre 1968 y 1969. En estos se incluyeron canciones de contenido político explícito, con una perspectiva antiimperialista. Entre ellos destacamos el LP Por Cuba y Vietnam (1969), de Rolando Alarcón, con acompañamiento del dúo Los Emigrantes. ${ }^{11}$

En este disco la solidaridad de Chile con ambas luchas revolucionarias se hace explícita en un mismo álbum. El lado A, dedicado a la revolución cubana, comienza con una composición de Alarcón llamada "Pregúntale a Cuba, hermano", donde se exaltan los hombres que "en su gesta de valor" terminaron con la "noche oscura", permitiendo que el pueblo alcanzase su dignidad. Además del texto que directamente apoya la causa revolucionaria de Cuba, el gesto de componer la canción en ritmo de son cubano, usando además un bongó, es relevante. Especialmente porque en estos años el bongó aún no era usado masivamente en Chile ni los músicos de la Ncch eran muy asiduos a los géneros "tropicales" o "afrocubanos" en los que se usaba ese instrumento.

Las canciones de esta sección de homenaje a la revolución cubana exaltan a dos de sus líderes más reconocidos, a Fidel Castro y al Che Guevara. Por ejemplo, encontramos la canción "Se llama Fidel”, compuesta por Alarcón en

${ }^{11}$ Antes, en 1966, Alarcón había grabado "Canto guajiro", que también le rinde homenaje a la revolución cubana. Este disco corresponde al segundo LP producido bajo el sello Tiempo, creado por el mismo Alarcón para difundir su producción más politizada. Respecto a la difusión de música comprometida en Chile, véase Schmiedecke (2014b); sobre Rolando Alarcón, véase Valladares y Vilches (2009). 
conjunto con Jesús Orta Ruiz y Enrique San Martín -este último, integrante de Los Emigrantes-; y otras dos canciones de autoría de los cubanos Eduardo Saborit ("Sin bandera") y Carlos Puebla ("Carta al Che"). A excepción de "El valle de Yuro" - una cueca de Enrique San Martín incluida en el lado A-, todas son interpretadas en ritmos cubanos, contribuyendo así a situar al oyente en aquel ambiente revolucionario. Es decir, se comienzan a asumir ciertos géneros cubanos, como el son, la guajira o el bolero, como expresión de la revolución cubana. Volveremos a esto más adelante, con otros ejemplos musicales.

En el lado B del disco, Rolando Alarcón tematiza la guerra en Vietnam. Aquí las canciones se dedican a denunciar la destrucción causada por los invasores y a celebrar la resistencia vietnamita, representada por el "héroe" Ho Chi Mihn. A diferencia de lo que se hacía con las canciones en solidaridad con la revolución cubana, en el caso de Vietnam no se empleó la estrategia de usar géneros locales. Probablemente esta diferencia respondía al desconocimiento de las tradiciones musicales de ese país de un sur tan lejano como era el Vietnam de los años setenta. En este caso, los homenajes se limitan al texto poético de las canciones.

Entre ellas, resulta particularmente interesante la versión que Alarcón graba de "Su nombre puede ponerse en verso", poema del cubano Félix Pita Rodríguez musicalizado por Pablo Milanés en 1968. Este homenaje que los cubanos habían hecho al pueblo de Vietnam es tomado por Alarcón con la misma finalidad -es decir, Cuba sirve también como un puente para conectar la lucha vietnamita con la chilena. Este recurso ya se había usado un año antes, cuando Quilapayún grabó una versión propia de la canción "La bola”, del cubano Carlos Puebla, conocido popularmente como el cantor de la revolución cubana. "La bola" es un collage de canciones cubanas que mezcla diferentes estilos, incluyendo géneros afrocubanos, y termina en ritmo de bolero con una referencia a "Un Fidel que vibra en la montaña, un rubí, cinco franjas y una estrella”. Mediante estas estrategias, tanto Rolando Alarcón como Quilapayún, no sólo expresaban su solidaridad con ambas revoluciones, sino que también sumaban la causa chilena a esta lucha más amplia contra el imperialismo.

Un segundo disco en homenaje a la resistencia vietnamita es X Viet-nam (1968), de Quilapayún. Este tema se concentra en la primera canción, homó- 
nima, mientras que las siguientes homenajean otras luchas. ${ }^{12}$ La canción "Por Vietnam" denuncia la invasión yankee - "águila negra" - al "heroico pueblo en Vietnam" y anuncia el fracaso de las tropas estadunidenses, rematando en el último verso: "yankee cuidado, cuidado, ya caerás, el guerrillero te vencerá". Aunque esta es la única canción del disco que tributa la lucha vietnamita, la carátula, donde se muestra la imagen de un guerrillero vietnamita levantando un fusil en gesto heroico, es suficientemente elocuente.

La significación de esta canción se refleja en que fue incluida en el documental homónimo producido en 1969 por el Centro de Alumnos del Instituto Pedagógico de la Universidad de Chile. Dirigido por Claudio Sapiaín y Álvaro Ramírez, este cortometraje tematiza la marcha por Vietnam, realizada entre el 6 y el 11 de septiembre del mismo año, cuando aproximadamente 3000 jóvenes chilenos marcharon de Santiago a Valparaíso en solidaridad con la lucha vietnamita (Gómez, 2014). Aquí se ponen en diálogo filmaciones de la guerra en Vietnam con imágenes de la manifestación y la canción de Quilapayún, cuyo ritmo y carácter refuerzan el sentido de avance y fuerza de la marcha (Farías, 2019, pp. 241-215). La letra de la canción dialoga de manera directa con las imágenes, por ejemplo, cuando se ve en pantalla a aviones bombarderos, se oye el verso "águila negra ya caerás". Pero también, imbuida de significaciones, esta canción -cantada a varias voces- potencia el simbolismo del canto colectivo que es transferido metafóricamente a los manifestantes, retratando su poder grupal (p. 215).

Las canciones y discos comentados hasta aquí exaltaban la figura heroica del guerrillero. ${ }^{13}$ Sin embargo, algunos de los músicos de la Ncch se vieron conflictuados por las diferencias de los procesos revolucionarios de Vietnam y Cuba con el caso chileno. Esta problemática se potenció especialmente con las campañas electorales que llevarían a Salvador Allende a la presidencia en 1970. De este modo, los tributos musicales a la revolución cubana y la resistencia vietnamita comenzaron a chocar con el proceso chileno.

12 Por ejemplo, hay canciones en homenaje a la revolución española, como "Que la tortilla se vuelva" (Chicho Sánchez Ferlosio) y "El turururú"; a los partisanos italianos "Mamma mia dame cento lire"; además de canciones de denuncia de Violeta Parra, como "Qué dirá el Santo Padre" y "Los pueblos americanos".

${ }_{13}$ Otros ejemplos son: "Camilo Torres" y "A Cochabamba me voy", grabadas en 1969 por Víctor Jara; "Canción fúnebre para el Che Guevara”, "Cuecas de Joaquín Murieta”, "Bella ciao”, "Por montañas y praderas" y "Carabina 30-30", grabadas entre 1968 y 1969 por Quilapayún; "El cautivo de Til-Til”, grabada en 1968 por Patricio Manns. 
A partir de entonces, los músicos de la Ncch no sólo esquivaron el uso de conceptos revolucionarios alusivos a la vía armada, sino que también explicitaron la particularidad del caso chileno: la vía electoral. Al mismo tiempo, los sellos grabadores tradicionales e incluso DICAP, que era mantenido por el Partido Comunista de Chile, al cual gran parte de los músicos de la Ncch estaban afiliados, demostraron resistencias a que las canciones reivindicaran la vía armada.

Respecto a las producciones de DICAP, por aquel entonces llamado Jota Jota, el músico Eduardo Carrasco comenta en su libro sobre Quilapayún que durante la producción del LP X Viet-nam (1968):

Surgieron, además, algunos problemas políticos acerca del contenido de las canciones: fuimos citados varias veces para discutir los textos, que eran puntillosamente analizados para que no fuera a haber en ellos contradicciones con la línea del partido. Una de las canciones, motivaba particular inquietud, la "Canción Fúnebre al Che Guevara". El Che era en Chile un símbolo mirista, y se corría el riesgo de hacerle propaganda al enemigo. Como los dirigentes de la Juventud no se ponían de acuerdo, el problema se llevó a la dirección del Partido. El texto fue sometido al Secretario General, Luis Corvalán, quien dio su aprobación: el Che era un comunista, y los ultras no tenían por qué apropiarse con exclusividad de su imagen (Carrasco, 2003, p. 129).

La caracterización del Movimiento de Izquierda Revolucionaria (MIR) -defensor del modelo cubano de transición al socialismo- como "enemigo" explicita las divisiones al interior de la izquierda chilena y deja entrever los límites que se impusieron a los acercamientos entre los dos países. Si hacia finales de los años sesenta los músicos se mostraban seducidos por la idea de la vía armada, la conformación de la up y la definición de un programa de gobierno común a las principales organizaciones de izquierda llevaron a un cambio de discurso.

Por ejemplo, en 1967, Víctor Jara lanzó por la multinacional EMI Odeon un disco sencillo que incluía "El aparecido", una composición de su autoría en homenaje al "Che" Guevara. Impedido por la casa grabadora de registrar en el sello del vinilo una dedicatoria explícita, Jara escribió simplemente: "A E. (Ch). G.", aludiendo a Ernesto (Che) Guevara (Jara, 2007, p. 123). Esta canción la grabó más adelante el conjunto Inti-Illimani en el álbum Autores chile- 
nos (1971), con un arreglo realizado por el compositor Luis Advis que incluye quena, charango, tiple colombiano y bombo legüero al estilo argentino.

Por su parte, Quilapayún grabó en su LP Quilapayún 3 (1969), también lanzado por EMI Odeon, dos canciones que remitían al Che: "Elegía" (también difundida como "Elegía al Che Guevara"), de Eduardo Carrasco, y "Ñancahuazú" ${ }^{14}$ de Patricio Castillo. Es interesante como ambas, sin tener texto, rinden un homenaje al guerrillero argentino. La primera comienza con una guitarra arpegiando y otra haciendo la melodía, a la cual se suman las voces masculinas del conjunto cantando suave y solemnemente en el estilo que en la ópera se conoce como "boca chiusa" o "coro a boca cerrada" ${ }^{15}$ Luego de repetir la melodía, la canción crece en sonido e intensidad, la guitarra comienza a rasguear y las voces a cantar "ohh", enfatizando la épica del guerrillero. Para finalizar, retoma la misma suavidad y sutileza del comienzo, enfatizando, introspectivamente, la figura del mártir.

Es llamativo que sólo un año después de su grabación esta canción fuera incluida en el filme Venceremos (Chaskel y Ríos, 1970), el cual documenta el fuerte y "persistente contraste entre la vida de la clase alta y la clase trabajadora" (Farías, 2019, p. 216). El uso de "Elegía” en el filme tiene una doble significación: remitiéndose al sentido más textual, alude directamente al Che Guevara, pero siguiendo una interpretación intertextual, representa al levantamiento del pueblo chileno a pesar de la fuerte represión hacia la clase trabajadora. El crescendo de esta canción, que va de lo más suave y sutil a lo más fuerte e intenso, ilustra la creciente confrontación de clases al interior de la sociedad chilena y enfatiza el carácter de mártir de los trabajadores que, con conciencia revolucionaria, se enfrentan a la policía y la oligarquía en una protesta (Farías, 2019, pp. 216-217).

A su vez, la canción "A Cuba” (aunque fue compuesta en 1969, se editó en disco en 1971) de Víctor Jara, es ilustrativa de la manera en que el compositor "se integra con entusiasmo al proyecto de hacer una revolución a la chilena”, según destaca Rolle (2005, p. 7). La canción rinde un homenaje a la revolución cubana y a sus líderes, posicionándolos como herederos de José Martí, es decir, continuadores de la lucha por la liberación de América del dominio

${ }^{14}$ La guerrilla Ñancahuazú o Ejército de Liberación Nacional de Bolivia fue la fuerza guerrillera comandada por Che Guevara en ese país entre 1966 y 1967, cuando fue asesinado en combate. La canción es un tema instrumental que usa instrumentos y ritmos andinos de manera muy protagónica, como el charango, aludiendo al imaginario andino y boliviano.

${ }^{15}$ Cantar sin abrir la boca, proyectando la voz con la letra eme. 
imperialista. En este sentido, Cuba sería un ejemplo a seguir por los países hermanos: "Si yo a Cuba le cantara, / le cantara una canción / tendría que ser un son, / un son revolucionario, / pie con pie, mano con mano, / corazón a corazón, / corazón a corazón, / Pie con pie, mano con mano, / como se le habla a un hermano, / si me quieres, aquí estoy, / ¿qué más te puedo ofrecer, / sino continuar tu ejemplo? / Comandante compañero, / ¡viva tu revolución!"

Este homenaje se refuerza por la interpretación en ritmo de son (primera parte) y de guajira (segunda parte), utilizando instrumentos de percusión característicos de dichos géneros, como el bongó, el güiro y las maracas.

Es importante mencionar que, desde los años cincuenta en Chile, este tipo de instrumentos los utilizaban ampliamente las orquestas de música bailable, etiquetadas como "tropicales" y que no tenían una connotación política clara como la Ncch. Es decir, los géneros e instrumentos afrocubanos estaban más asociados a las orquestas bailables tropicales que al folclor latinoamericano (véase Karmy, Vargas, Mardones y Ardito, 2013). Poco a poco, y con motivo de homenajear la revolución cubana, los músicos de la Ncch comenzaron a incorporar estos géneros e instrumentos en su repertorio, ${ }^{16}$ como haría Rolando Alarcón en su disco Por Cuba y Vietnam (1969), y Víctor Jara en su canción "A Cuba".

Sin embargo, con "A Cuba", Jara no se limita a exaltar la revolución cubana, sino que también establece un límite entre su modelo revolucionario y el caso chileno, distinguiendo y definiendo el camino escogido por la UP: "Como yo no toco el son / pero toco la guitarra / que está justo en la batalla / de nuestra revolución / será lo mismo que el son / que hizo bailar a los gringos, / pero no somos guajiros / nuestra sierra es la elección”. Estos versos, con los que concluye la canción, dan luces sobre su estribillo, en el que Jara sugiere que el lugar para "conocer a Martí y a Fidel", "conocer los caminos del Che" o "trabajar a la caña de azúcar" es Cuba -y no Chile-. Aquí hay un mensaje claro de Jara -en tanto miembro del Comité Central de las Juventudes Comunistas- para los sectores más radicalizados de la izquierda, con los cuales busca disputar la filiación a la revolución cubana.

${ }^{16}$ Respecto a la elección de géneros musicales usados en las "canciones contingentes" que Quilapayún lanzaría en 1973, Eduardo Carrasco relata: "Esos ritmos fueron elegidos porque eran populares y nosotros queríamos ser escuchados. En esa época -como hoy día la música afrocubana- tenía mucho arraigo en el pueblo. Se tocaba en las fiestas y se bailaba" (Ardito, Karmy, Mardones y Vargas, 2016, p. 281). 
En "A Cuba", por tanto, reconocemos lo que vendría a ser un eco de las relaciones entre la revolución cubana y la vía chilena al socialismo: por un lado, la solidaridad entre los dos procesos; por otro, la demarcación de especificidad de cada uno de ellos.

\section{DE LA CANTATA AL ROCK: DURANTE LA UP}

Durante la UP, la cantidad de canciones grabadas por músicos de la Ncch que exaltaban la figura del guerrillero y los movimientos de lucha armada fue menor que en el periodo anterior. ${ }^{17}$ Sin embargo, los homenajes a Cuba y Vietnam persistieron. En 1971, Quilapayún grabó su LP Vivir como él (Nguyen Van Troi) que, en la cara A incluye la cantata popular homónima, compuesta por el cubano Frank Fernández, con interludios instrumentales escritos por el chileno Luis Advis, dedicada al héroe vietnamita Nguyen Van Troi. Advis había escrito en 1970 la "Cantata Popular Santa María de Iquique", sentando un importante precedente en la música chilena al mezclar elementos del folclor, la música popular y académica en una pieza musical de largo aliento, con relato y otros elementos dramáticos. ${ }^{18}$ Es interesante cómo esta nueva cantata popular, por su estilo e instrumentación, remite a esta primera cantata de Advis. Es también una obra de largo aliento (de casi 19 minutos) que denuncia un hecho histórico trágico -en este caso, el fusilamiento de Nguyen Van Troi-, interpretada por Quilapayún y Héctor Duvauchelle, en el relato, e interludios instrumentales.

Aquí las voces masculinas del conjunto, el uso de las cuerdas (guitarra y charango) y las quenas en contrapunto enfatizan el dramatismo y la épica que busca transmitir la obra. Un ejemplo de esto es el fragmento en el que se canta "A pesar del sufrimiento / cantamos, cantamos" con una entonación de la voz muy suave que sigue una estructura armónica inesperada. Esta no sólo enfatiza el dramatismo de estos versos, sino que musicalmente expresa la contraposición del dolor y la alegría que habrían sentido los vietnamitas prisioneros. Con los versos siguientes, "porque mientras la carne sufre / el

${ }^{17}$ Sobre los diferentes posicionamientos de los músicos de la NCch respecto a la lucha armada durante la UP y en el exilio, véase Gomes (2015 y 2018); Jordán (2010).

${ }^{18}$ Sobre la mezcla de elementos de la música folclórica, popular y docta, véase Gómez y Rodríguez (2018); Peña (2014). Sobre el impacto de la "Cantata Popular Santa María de Iquique”, véase Guerrero (2013); Karmy (2014a y 2014b); Mamani (2014). 
pensamiento / está en el día de la victoria”, la armonía resuelve enfatizando la épica del triunfo. En el interludio inmediatamente siguiente, se oyen dos quenas en contrapunto, con ciertas disonancias, acompañadas de guitarra y charango rasgueando en ritmo de taquirari -género de la tradición musical andina- y otros recursos dramáticos ya usados en los interludios de "Santa María de Iquique".

En "Vivir como él", la legitimación del uso de la violencia como un medio de defensa se hace explícita. Nguyen Van Troi es tomado como un símbolo de la lucha antiimperialista y encarna los valores de patriotismo, coraje y justicia. Al contrario, Estados Unidos aparece representado como enemigo de la patria (invasores, imperialistas, traidores, asesinos) y, por lo tanto, "Hay que darle muerte al invasor. / Hay que matarlo". La cantata termina con la afirmación de que la muerte de Nguyen Van Troi no fue en vano, porque "Por Vietnam estamos dispuestos a dar / hasta nuestra propia sangre".

Este espíritu coincide con las palabras de Fidel Castro pronunciadas en el discurso de clausura de la Conferencia Tricontinental, en 1966 (Schmiedecke, 2015, pp. 229-231):

El imperialismo será inevitablemente derrotado. ¿Quiénes nos han enseñado esa lección? Nos la han enseñado los pueblos. ¿Quién entre los pueblos nos ha dado en estos tiempos la más extraordinaria lección? El pueblo de Viet Nam [...] Justo es que dediquemos nuestro recuerdo a los que se han sacrificado por la victoria de sus pueblos, a los que han caído víctimas del imperialismo en todos los continentes; $y$ que nos propongamos ser siempre fieles a esa causa, ser siempre fieles, en Asia, en África y en América Latina, a la causa de los que han dado su vida y su sangre por la liberación de los pueblos (Castro, 1966).

En la cara B del mismo LP, Quilapayún incluye la canción "Segunda declaración de La Habana", ${ }^{19}$ una adaptación del discurso homónimo pronunciado por Fidel Castro el 4 de febrero de 1962. Con texto de la dramaturga Isidora Aguirre y música de Luis Advis, la canción comienza con una reproducción de la parte final del discurso, luego entran los instrumentos (guitarras y quenas). Musicalmente, es importante mencionar que la guitarra, en

${ }_{19}$ Esta canción fue parte de la obra teatral Los que van quedando en el camino (1968), de Isidora Aguirre, donde Advis colaboró como compositor. La obra trataba sobre una matanza de campesinos ocurrida en el centro-sur cordillerano en 1932. 
ritmo de marcha, hace un rasgueo persistente que le da un sentido épico a la canción. El uso de las voces masculinas y de los instrumentos de tradición andina potencian este sentido épico y de convicción revolucionaria. Las voces del conjunto cantan por encima de las palabras de Fidel, y se intercalan fragmentos en los que predomina la voz del líder cubano, mientras que en otros esta es casi inaudible por debajo de las voces de Quilapayún. La letra cantada recupera segmentos del discurso, aumentando algunos versos y alterando otros:

Ha llegado la hora en que el pueblo / reivindique el derecho de ser / dueño al fin de su tierra robada / tierra inmensa que ha de germinar / con la paz del empeño ganado / con sus manos de fuerza tranquila; / ahora sí que la historia tendrá que contar / con los pobres de América. / [...] / Este pueblo levanta sus puños / este pueblo levanta su voz / ya no mira hacia el suelo, ni calla / ya la sombra se empieza a aclarar / nuestra América rompe el engaño / y su pueblo ha tomado conciencia / ahora sí la historia tendrá que contar / con los pobres de América.

Aquí hay una noción de un pasado común a los diferentes países latinoamericanos que fundamenta la reivindicación de unión presente para combatir al enemigo imperialista. Las referencias a escenarios representativos de diferentes localidades (sierras, selvas, ciudades, litoral) refuerzan esta idea de que el "despertar" constituiría un proceso único, de amplitud continental, iniciado por la revolución cubana con el objetivo de transformar a los pobres, explotados y postergados en sujetos de la historia (Schmiedecke, 2015, pp. 222-223).

Considerando el contexto en el que se grabó esta canción -en el Chile de la UP, por artistas que apoyaban abiertamente este gobierno, en un disco producido por el sello del Partido Comunista-, podemos leer que, además de homenajear a la revolución cubana, hay aquí una intención de insertar a la "experiencia chilena" en un cuadro más amplio y de validarla como proceso revolucionario. Esta validación la dio el propio Fidel Castro durante su visita oficial a Chile a fines de 1971. En un discurso pronunciado en el Teatro Municipal de Santiago, el líder cubano criticó a los que trataban de presentar el proceso chileno en contradicción con la ideología de la revolución cubana. Castro recordó que ya en la Primera y la Segunda Declaraciones de La Habana "nosotros planteábamos la forma de la lucha armada revolucionaria allí donde todos los caminos estuviesen cerrados para el pueblo, y que nues- 
tra revolución nunca tuvo ninguna contradicción con el proceso chileno", y que al darse cuenta de la posibilidad real de una victoria de Allende en las elecciones presidenciales de 1970, "nuestra posición fue apoyar públicamente, expresar nuestro optimismo, nuestra creencia en la posibilidad de esa vitoria" (Cuba-Chile, 1972, p. 381).

Así como las manifestaciones de apoyo al gobierno de la up por parte de Castro no significaron el abandono de su perspectiva insurreccional para los pueblos del Tercer Mundo, los homenajes de los músicos de la NCch a líderes guerrilleros y procesos revolucionarios librados por la vía armada, no deben ser entendidos necesariamente como un cuestionamiento a la vía chilena. De todas las canciones grabadas entre 1970 y 1973 en el marco del movimiento, sólo algunas composiciones de Patricio Manns asumen esta perspectiva. En su único LP lanzado durante la UP, Patricio Manns (1971), el músico incluyó "Su nombre ardió como un pajar", en la cual le rinde un homenaje a Che Guevara. Esta canción cuenta con acompañamiento del conjunto del rock Los Blops $y$, al igual que en otras canciones de este disco, enaltece la figura del guerrillero. A diferencia de la mayoría de los músicos ligados a la NCch, que eran militantes de los partidos de la UP, Manns militaba en el MIR, organización que se mantuvo fuera y a la izquierda del gobierno de Allende. Mientras que algunas de sus composiciones incluidas en este disco sugieren que la lucha armada sería también una opción, otras recalcan que la victoria de la up estaba lejos de significar el triunfo del socialismo en el país (por ejemplo, "No cierres los ojos").

La banda Los Blops también acompañó a Víctor Jara en la grabación de "El derecho de vivir en paz" (1971) y a Ángel Parra en su versión de "Cuba va" (1972), una composición de los cubanos Pablo Milanés, Noel Nicola y Silvio Rodríguez. "El derecho de vivir en paz" retoma el tema abordado en la obra Viet Rock, que Jara dirigió en 1969 en el Departamento de Teatro de la Universidad de Chile (Dетuch). La pieza es una adaptación del texto homónimo escrito por la dramaturga estadunidense Megan Terry en la cual el mensaje pacifista prevaleciente en la versión original da lugar a la crítica explícita a la acción imperialista de los invasores. ${ }^{20}$

Siguiendo la misma línea, la canción le rinde tributo al líder vietnamita, el "poeta Ho Chi Minh" y denuncia el "genocidio y napalm" llevado a cabo por las tropas estadunidenses en Vietnam, al tiempo que exige "el derecho

${ }^{20}$ Sobre la pieza teatral, véase Sepúlveda (2001, pp. 140-146). 
de vivir en paz". Llama la atención la dulzura del canto y la insistencia en el amor como fuerza de lucha. Por ejemplo, en la última estrofa, Jara hace un gesto de cercanía y familiaridad, tratando al vietnamita revolucionario como "Tío Ho", y ofreciéndole "nuestra canción" que "es fuego de puro amor / es palomo palomar / olivo del olivar / es el canto universal / cadena que hará triunfar / el derecho de vivir en paz".

Los Blops aderezaron esta canción "con guitarras eléctricas distorsionadas y órganos de acento psicodélico” (Ponce, 2008, p. 127), asignándole un carácter rico en significaciones. Es interesante que esta ofrenda si bien se hace desde la Ncch -y por parte de un artista emblemático del movimiento- se hace incluyendo sonidos, como el de la guitarra eléctrica, que para muchos eran interpretados como símbolos del imperialismo estadunidense, misma potencia que oprimía a Vietnam. ${ }^{21}$ Aunque el propio Jara se refirió a la intención de utilizar el rock como una "experiencia de "invasión de la invasión cultural" (Jara, 2007, p. 162), esta mezcla sonora no estuvo exenta de críticas por parte de los sectores más dogmáticos de la izquierda chilena. ${ }^{22}$ Como recuerda Eduardo Gatti, quien grabó la guitarra eléctrica: "Nosotros estábamos sufriendo acusaciones tan infantiles como [...] que la guitarra eléctrica era un instrumento imperialista" (Karmy, 2012, p. 218). En la misma línea, Juan Pablo Orrego, también integrante de Los Blops, recuerda que: "A pesar de no ser de partido ni calzar con los cánones de la música política, igual nos permitían mostrar nuestra música ante los trabajadores. Era muy loco porque después de las tocatas había foros, y siempre alguien decía que le habían enseñado que estos instrumentos eran imperialistas" (Ponce, 2008, p. 128).

Esta crítica tenía lógica en tanto la Ncch se abocó a difundir ritmos e instrumentos folclóricos de América Latina y, en su identificación con la izquierda y las revoluciones tercermundistas, denunció las políticas intervencionistas estadunidenses. La postura antiimperialista de los sectores de la izquierda y de la Ncch llevaron a que muchos de sus representantes se opu-

${ }^{21}$ El uso de la guitarra eléctrica generó controversia en estos años, tanto en diferentes países latinoamericanos como también en Estados Unidos. Entre ellos, sobresale el caso de Brasil, donde en 1967 se realizó la "Passeata contra a guitarra" (Marcha contra la guitarra). Entre los manifestantes, estaban importantes nombres de la Música Popular Brasilera (МРв) identificados con la izquierda política. Sobre este tema, véase Guimarães (2014). Dos años antes, en Estados Unidos en 1965, Bob Dylan había optado por desafiar la regla implícita del folk estadunidense, interpretado con sonidos acústicos, por instrumentos eléctricos generando gran controversia y críticas de su público. Sobre esto, véase Marshall (2007).

${ }^{22}$ Sobre las relaciones entre el rock y la NCch, véanse Salas (2003) y Farías (2014). 
sieran a las músicas de origen anglo, como el rock, por asociarlas al imperialismo estadunidense. Además, el rock y la psicodelia estaban asociados al movimiento hippie, en el que los jóvenes tendían a evadir la realidad en vez de comprometerse activamente con la lucha política. ${ }^{23}$

La apertura de algunos músicos de la NCch al rock consideramos que fue influenciada, entre otros, por el Grupo de Experimentación Sonora del Instituto Cubano de Arte e Industria Cinematográficos (GEs-ICAIC) y la Nueva Trova Cubana, que contribuyeron a disminuir el prejuicio sobre los instrumentos eléctricos y otros recursos musicales asociados al rock. ${ }^{24}$ También por el rol político que rockeros anglos estaban tomando al denunciar el imperialismo estadunidense -en especial, se posicionaron contra la guerra de Vietnam ${ }^{25}$ - y por la experiencia de algunos de los propios músicos de la NCch. Este es el caso de Víctor Jara, quien se asumía fan de Los Beatles y ya había versionado canciones grabadas por los estadunidenses Pete Seeger y Malvina Reynolds. ${ }^{26}$ Según recuerda Gatti: "[Víctor] escuchaba todo tipo de música, estaba abierto a todo. Y en ese sentido, era una persona muy culta. Víctor había estado en Inglaterra, era amigo de Donovan, un cantautor escocés que fue muy conocido en esa época, muy grande. O sea, Víctor era una persona de mundo, y por lo tanto respetaba todas las manifestaciones" (Karmy, 2012, p. 219).

De este modo, podemos interpretar el ejercicio de mezclar la estética de la Ncch con la del rock psicodélico, como el de Los Blops, como un llamado a la coexistencia en paz entre los militantes del PC, la NCch y los "lolos" hippies. Al incorporar los elementos del rock psicodélico a "El derecho de vivir en paz", Jara buscó también "deconstruir el imaginario totalizante que identificaba todo lo anglosajón como imperialista, poniendo en discusión la

${ }^{23}$ Esta rencilla fue retratada en el documental Descomedidos y chascones (Flores, 1973), dando cuenta que la diferencia también respondía a un asunto de clase. Aquí se ve a jóvenes de clase trabajadora defendiendo la disciplina como expresión del compromiso político y criticando a sus pares de clases acomodadas que experimentaban con drogas, por evadir sus responsabilidades como sujetos históricos.

${ }^{24}$ Sobre el GES y la Nueva Trova, véase Villaça (2004).

${ }_{25}$ Como, por ejemplo, la épica performance de Jimi Hendrix en el Festival de Woodstock de 1969, en la que usando sonidos de distorsión imitó sonidos de metralletas y explosiones, dando un claro mensaje antiguerra.

26 "El martillo" grabada en el disco Pongo en tus manos abiertas... (1969) es original de Pete Seeger ("If I Had a Hammer"). En su disco El derecho de vivir en paz (1971), Jara grabó también "Las casitas del barrio alto", una versión de "Little Houses" de Malvina Reynolds pero popularizada por Pete Seeger a inicios de los sesenta. 
dicotomía entre música de origen foráneo (como el rock) y música latinoamericana, como si se tratara de oposiciones del tipo falsedad / autenticidad; imperialismo / revolución, o bien, opresores / oprimidos" (Karmy, 2012, p. 219).

Otro grupo de la Ncch que incorporó elementos del rock fue Amerindios, dúo formado por Julio Numhauser y Mario Salazar. En su primer disco (Amerindios, 1970), "si bien no hay canciones explícitamente rockeras", como sería en los discos posteriores, sí expresa "cierta actitud que funde elementos irónicos en las letras y un carácter musical bastante rupturista de algunas piezas" (Farías, 2014, p. 149). Sus canciones critican el imperialismo y belicismo estadunidense al tiempo que reivindican las luchas cubana y vietnamita. Este disco comienza con dos canciones del compositor chileno Sergio Ortega, "Nixon" y "Una vez un yankee yo encontré". En ellas se utilizan estrategias intertextuales que requieren que el escucha modifique sus "modelos de interpretación", ${ }^{27}$ como la ironía. Esta, como ejercicio intertextual, puede actuar de distintos modos, entre los cuales se encuentran la burla o sátira y el cinis$m o{ }^{28}$ ambos presentes en estas canciones.

"Nixon" comienza con sonidos de bombardeos y metralletas, seguidos de una guitarra, un bongó y dos voces que lentamente van tomando ritmo de guaracha cubana. La canción pregunta repetidas veces quién matará a Richard Nixon, como invocando venganza por las muertes provocadas por el líder estadunidense, las que se detallan en la segunda estrofa: "Che Guevara no se mata / ni a los negros se destruye / en Vietnam desde hace tiempo / sangre yankee fluye y fluye". En el estribillo se especula sobre quién matará a Nixon: "una madre vietnamita será / o la esposa de un negrito, quizás / una baja en las acciones será / o tu vicepresidente, quizás”. Sospechar en primer lugar de mujeres resulta interesante, puesto que por el juego intertextual de

${ }^{27}$ López Cano (2005, p. 8) define los modelos de interpretación como "un conjunto de rutinas y operaciones de inferencia complejas que aplicamos una y otra vez a circunstancias similares de cognición. Son muy flexibles y variables y aceptan la inclusión o supresión de estrategias emergentes. Se sustentan en acciones de inferencia por inducción, deducción y abducción. El modo de organizar estas operaciones va desde las operaciones lógicas estrictas como el silogismo, hasta la analogía, metáfora y otros procesos retóricos y de lógica no lineal. De la adecuada articulación de diferentes modelos de interpretación aplicados a la misma canción, depende la coherencia."

${ }^{28}$ Este opera de dos maneras: "a) cuando se rompe la expectativa de la aparición de un tópico que introduzca una ironía que postule algún juicio de valor en situaciones que requieren ser reprobadas. De este modo se da una apología de lo moralmente correcto, o b) cuando el cambio de tópico no modifica los contenidos pero cambia la perspectiva con que éstos son enunciados" (López Cano, 2005, p. 9). 
la canción, estas se muestran como sujetos inofensivos. Más aún, considerando que tanto en la NCch como en el imaginario del "hombre nuevo" las mujeres fueron tratadas como sujetos relativamente pasivos, que acompañan $\mathrm{y}$ ayudan en los procesos revolucionarios, pero no como protagonistas. Al dar cuenta que estas mujeres existen en relación otros a sujetos postergados ("una madre vietnamita" o la "esposa de un negrito"), es exagerada su irrelevancia y lo inofensivas que podrían llegar a ser. Al poner a estas mujeres en el mismo grado de importancia que "una baja en las acciones", se exagera aún más su irrelevancia. Y al mismo tiempo ubica al "vicepresidente" de Estados Unidos en este mismo nivel de poca importancia. En su conjunto, este ejercicio de ironía se exagera con la repetición de la onomatopeya del sonido de una metralleta -"ratatatá"-. No es que Amerindios y Ortega realmente crean que alguien matará a Nixon ni que aboguen por la vía armada, sino que, mediante la estrategia de la ironía, satirizan la tragedia.

Por su parte, "Una vez un yankee yo encontré" es un homenaje a la resistencia vietnamita, pero que en vez de exaltar la figura del guerrillero como habían hecho otras canciones contemporáneas, condena directamente a Nixon ubicándolo "en el sitial privilegiado de la bestialidad" junto a "Franco, Hitler y Mussolini / cuatro jerarcas de la escoria / cuatro canallas de la historia". El uso del bolero en esta canción, además de hacer referencia a un género musical típico de Cuba $-\mathrm{y}$ de ese modo explicitar la solidaridad con dicho país- es también una estrategia intertextual de ironía. Aquí se usa el bolero con su progresión armónica, instrumentación y estilo típicos, pero que en vez de cantar temáticas romántico-amorosas, como comúnmente se ha hecho -y se espera que se haga en este género- la canción insulta al presidente de Estados Unidos. El contraste entre el género, el estilo y la letra de la canción consiste en un interesante juego semiótico que provoca un cambio de expectativa por parte del escucha. Amerindios y Ortega se burlan de Nixon con una canción construida armónica y melódicamente dentro de las reglas estilísticas del bolero, pero en la que ni el contexto ni la letra se ajustan al género. En este sentido, se produce una ironía, una sátira, rompiéndose, por una parte, la expectativa de los contenidos textuales que se esperan, y por otra, exaltándose la contradicción de la retórica amorosa del género del bolero y la letra ofensiva que insulta a Nixon.

La tercera canción de este disco es una versión de "David y Goliat" del cubano Carlos Puebla y sus Tradicionales grabada por Amerindios como "Los vietnamitas". Tal como lo enuncia su nombre, es un homenaje al pueblo de 
Vietnam que resistió a la invasión estadunidense, ahora en ritmo de son. Hace una analogía a la narración bíblica de David y Goliat, comparando a los vietnamitas con el primero -"son chiquititos"-y a los estadunidenses con el segundo -"son grandulones"-. ${ }^{29}$ Si bien Amerindios cambia el nombre de la canción, mantiene la analogía y la explicita en la presentación de la canción, donde relata en voz hablada: "David venció a Goliat como..." -luego del interludio vocal "pápara parapapapá”- completan la oración cantando "los vietnamitas". La versión de Amerindios mantiene el género del son pero le aumenta la velocidad. El sonido de la guitarra de la melodía de los interludios que hace de Carlos Puebla es reemplazado por las voces de Amerindios que cantan “pápara parapapapá”. Aquí el recurso del humor también está presente, pero ya no en referencias intertextuales como en el caso anterior, sino que directamente en la letra. La ironía de criticar a los "yankees" por sus características físicas - "parecidos a gigantes"-y ofenderlos con acusaciones que pueden resultar inofensivas - "algunos como elefantes / pero no tienen corazones"- en el contexto de una guerra genocida funciona humorísticamente. También, los cantantes cuentan al estilo de los rockeros anglo -"one, two, three, four"-, pero sin hacer un esfuerzo por pronunciar 'bien' el inglés, evidenciando que se trata de una burla más que de una impostación.

\section{CONCLUSIÓN}

A lo largo del artículo hemos dado cuenta de qué manera la izquierda chilena expresó su solidaridad hacia Cuba y Vietnam a través de la producción artística de la Ncch. Analizamos esta producción con el concepto de solidaridad transnacional Sur-Sur, en la que países del Tercer Mundo empatizan entre sí con las luchas por la igualdad y la liberación. Por la particularidad del caso chileno, en el que escoge la vía "pacífica", electoral, en vez de la vía armada, el discurso de solidaridad hacia Cuba y Vietnam no estuvo exento de conflictos al interior de la izquierda ni del movimiento de la Ncch.

Presentamos como un primer hallazgo que, desde antes que la up fuera gobierno, los músicos de la Ncch expresaron su solidaridad con las dos luchas revolucionarias. Sin embargo, desde fines de 1969 se hicieron notorios

${ }^{29}$ En la versión de Carlos Puebla se canta "son pequeñitos" y "grandullones", respectivamente. 
ciertos cambios. La exaltación a la figura del guerrillero y a los movimientos de lucha armada en este repertorio disminuyó significativamente pero no así el apoyo a la revolución cubana y a la resistencia vietnamita. Lo que cambió fue la manera en que las canciones expresaron este apoyo, utilizando nuevas estrategias intertextuales. Con esto, por una parte, los músicos chilenos se desmarcaban de la opción armada, y por otra, validaban la "vía chilena" y la insertaban en el contexto revolucionario del Tercer Mundo durante la guerra fría.

Un segundo hallazgo corresponde al uso de los géneros y estilos musicales y su identificación con las luchas revolucionarias. Dimos cuenta que para hacer referencia a la revolución cubana -y mostrar solidaridad con ella- se tendió a usar géneros e instrumentos típicos de Cuba. Esto ocurrió durante todo el periodo estudiado. Además de cantarse en ritmo de son, guajira o bolero, se usaron instrumentos como el bongó, el güiro y las maracas, que, en Chile, desde los años cincuenta, se usaban para otro tipo de repertorio, sin contenido político explícito, como el de las orquestas bailables de música tropical.

Respecto a los géneros musicales usados para cantarle a Vietnam, notamos que ocurría una situación diferente. No se usaron géneros ni instrumentos vietnamitas, sino que una amplia variedad de géneros, estilos e instrumentaciones, tanto anteriormente explorados por la NCch -como la cantata popular- como otros más novedosos. Por una parte, este vacío de referencias sonoras para representar a Vietnam y llevar al escucha a ese contexto revolucionario fue sorteado utilizando repertorio y géneros cubanos como puente, por ejemplo, versionando canciones cubanas, o bien creando composiciones propias en ritmos afrocubanos. Por otra, dio un espacio de libertad creativa en el que los músicos de la NCch pudieron explorar nuevos géneros, sonidos e instrumentos, desde la cantata al rock, utilizando tanto recursos dramáticos como humorísticos. Llama la atención que esta creatividad sonora se diera particularmente para cantarle a Vietnam y no a Cuba, cuyo repertorio se remitía más bien a los géneros afrocubanos. El uso del rock aquí desempeñó un papel importante; por un lado, ampliando los límites estilísticos de la Ncch y, por otro, conectándose con la canción protesta estadunidense contemporánea.

En suma, la Ncch utilizó la música como acción política, expresando solidaridad hacia las luchas revolucionarias de Cuba y Vietnam. Esta solidaridad dio cuenta de una identidad común, ayudando a sortear las diferencias culturales y las distancias geográficas entre dichos países, revindicados como pueblos hermanos. De este modo, sin necesariamente considerarlos como 
modelos a seguir, la Ncch hizo visible la importancia de apoyar de manera explícita esos procesos revolucionarios, señalando que, en última instancia, eso también significaba apoyar al propio proceso chileno.

\section{LISTA DE REFERENCIAS}

Ardito, L., Karmy, E., Mardones, A. y Vargas, A. (2016). ¡Hagan un trencito! Siguiendo los pasos de la memoria cumbianchera en Chile (1949-1989). Santiago: Ceibo.

Black, A. (2018). "Canto Libre": Folk music and solidarity in the Americas. En J. Stiles Mor y M. Suescun Pozas (eds.). The art of solidarity: visual and performative politics in cold war Latin America (pp. 117-145). Austin: University of Texas Press.

Calvo, P. (2018). La Organización Latinoamericana de Solidaridad (Olas) a través del boletín de información de su comité organizador (1966-1967). Revista de Historia Social y de las Mentalidades, 22(1), 155-185. Recuperado de http://www.revistas. usach.cl/ojs/index.php/historiasocial/article/view/3295/26002636

Carrasco, E. (2003). Quilapayún: la revolución y las estrellas. Santiago: RIL.

Casals, M. (2010). El alba de una revolución. La izquierda y el proceso de construcción estratégica de la "vía chilena al socialismo" 1956-1970. Santiago: LOM.

Castro, F. (1966). Discurso pronunciado por el comandante Fidel Castro Ruz, primer secretario del Comité Central del Partido Comunista de Cuba y primer ministro del Gobierno Revolucionario, en el acto de clausura de la Primera Conferencia de Solidaridad de los Pueblos de Asia, África y América Latina (Tricontinental), en el Teatro Chaplin, La Habana, el 15 de enero de 1966 [versión taquigráfica]. La Habana: Departamento de Versiones Taquigráficas del Gobierno Revolucionario. Recuperado de http://www.cuba.cu/gobierno/discursos/1966/esp/f150166e.html

Chartier, R. (2002). À beira da falésia: a História entre certeza e inquietude. Porto Alegre: Ed. UfRGs.

Chaskel, P. y Ríos, H. (1970). Venceremos. Santiago: Cine Experimental de la Universidad de Chile. Recuperado de http://cinetecavirtual.cl/cineteca/index.php/Detail/ objects $/ 2367$

Cuba-Chile. Encuentro simbólico de dos procesos históricos (1972). La Habana: Ediciones Políticas. Comisión de Orientación Revolucionaria del Comité Central del Partido Comunista de Cuba.

Farías, M. (2014). Cueca Beat: Diálogos entre el Rock y la Nueva Canción Chilena. En E. Karmy y M. Farías (comps.). Palimpsestos sonoros. Reflexiones sobre la Nueva Canción Chilena (pp. 139-161). Santiago: Ceibo. 
Farías, M. (2019). The politics of film music in Chile (1939-1973) (Tesis de doctorado inédita). University of Edinburgh, Escocia.

Featherstone, D. (2012). Solidarity: Hidden histories and geographies of internationalism. Londres: Zed Books.

Flores, C. (1973). Descomedidos y chascones. Santiago: Cine Experimental de la Universidad de Chile. Recuperado de http://cinetecavirtual.uchile.cl/cineteca/index. php/Detail/objects/2375

Gomes, C. (2015). "Quando um muro separa, uma ponte une": Conexões transnacionais na canção engajada na América Latina (anos 1960/70). São Paulo: Alameda.

Gomes, C. (2018). "Cada verso é uma semente no deserto do meu peito": exílio, resistência e conexões transnacionais na canção engajada latino-americana (anos 1970). (Tesis de doctorado inédita). Universidade de São Paulo, Brasil.

Gómez, M. (2014). Un bruit lointain? Les musiciens chiliens face à la Guerre du Vietnam (1965-1975). Transposition, 4. DoI: https://doi.org/10.4000/ transposition. 584

Gómez, M. y Rodríguez, J. (2018). "Entre la hoz y el martillo": vínculos entre música culta, folklore y política en Chile durante la Guerra Fría (1947-1973). Amérique Latine Histoire et Mémoire. Les Cahiers ALHIM, 35. DoI: https://doi.org/10.4000/ alhim. 6414

Guerrero, J. (2013). La cantata: el cruce entre lo culto y lo popular. Revista Musical Chilena, 222(67), 94-106.

Guimarães, V. (2014). A passeata contra a guitarra e a "autêntica" música brasileira. En C. Rodrigues, T. Luca y V. Guimarães (eds.). Identidades brasileiras: composições e recomposições (pp. 145-173). São Paulo: Editora unesp/Cultura Acadêmica. Recuperado de http://books.scielo.org/id/h5jt2/pdf/rodrigues-9788579835155-07.pdf

Independent Commission on International Development Issues (1980). North-South: A Programme for Survival. The Report of the Independent Commission on International Development Issues under the Chairmanship of Willy Brandt. Londres: Pan.

Jara, J. (2007). Victor, un canto inconcluso. Santiago: LoM.

Jordán, L. (2010). Cantando al MIR y al Frente: Cita y versión en dos canciones militantes de Patricio Manns. Ponencia presentada en el IX Congreso de la IASPM-AL, Caracas, Venezuela. Recuperado de http://iaspmal.com/index.php/2016/03/02/ actas-ix-congreso/?lang=pt

Karmy, E. (2012). "Ecos de un tiempo distante": La Cantata Popular Santa María de Iquique (Luis Advis-Quilapayún) y sus resignificaciones sociales a 40 años de su estreno. (Tesis de maestría inédita), Universidad de Chile, Chile. 
Karmy, E. (2014a). La Cantata Popular Santa María de Iquique: representaciones del obrero pampino y del hombre nuevo. En E. Karmy y M. Farías (comps.), Palimpsestos sonoros. Reflexiones sobre la Nueva Canción Chilena (pp. 99-116). Santiago: Ceibo.

Karmy, E. (2014b). "Remembrance is not Enough..." Cantata Popular Santa María de Iquique 40 years after its release. En P. Vila (ed.), The militant song movement in Latin America: Chile, Uruguay, and Argentina (pp. 54-68). Lanham: Lexington Books.

Karmy, E., Vargas, A., Mardones, A. y Ardito, L. (2013). El trencito rebelde: sobre cómo la cumbia se tomó las calles e hizo bailar a los serios intelectuales de la Unidad Popular. Revista Retrospectiva de la Corporación Chilena de Estudios Históricos, 1 , 57-75.

Larrea, A. (2008). 33 1/3 RPM: la historia gráfica de 99 carátulas 1968-1973. Santiago: Nunatak.

López Cano, R. (2005). Más allá de la intertextualidad. Tópicos musicales, esquemas narrativos, ironía y cinismo en la hibridación musical de la era global. Nassarre: Revista Aragonesa de Musicología, 1(21), 42-63.

López Cano, R. (2011). Lo original de la versión. De la ontología a la pragmática de la versión en la música popular urbana. Consensus, 16(1), 57-82.

Mahler, A. G. (2018). From the Tricontinental to the global South. Race, radicalism, and transnational solidarity. Durham: Duke University Press.

Mamani, A. (2014). Historia reciente, pasados lejanos. Disputas y resemantizaciones en torno a la masacre Santa María de Iquique. Trashumante, 3, 96-114. Recuperado de https://dialnet.unirioja.es/servlet/articulo?codigo=4959170.

Marshall, L. (2007). Bob Dylan: The never ending star. Cambridge: Polity.

Muhr, T. y Azevedo, M. (2019). Relações Sul-Sul em Educação: o programa ¡Yo, Sí Puedo! e a cooperação em educação do BRICs em foco. Revista Ibero-Americana de Estudos em Educação, 14(1), 2-30. DoI: https://doi.org/10.21723/riaee.v14i1.11730

Ossorio, J. (1967). Encuentro de la canción protesta. Casa de las Américas, 45, 139-144.

Party, D. (2019). Homofobia y Nueva Canción Chilena. El Oído Pensante, 7(2), 4263. Recuperado de http://ppct.caicyt.gov.ar/index.php/oidopensante/article/ view/15035/45454575768892

Pedemonte, R. (2008). Los acordes de la patria. Música y nación en el siglo XIX chileno. Santiago: Globo.

Peña, P. (2014) ¿Doctos populares? Advis, Ortega y Becerra, trilogía de límites confusos en el seno de la Nueva Canción Chilena. En E. Karmy y M. Farías (comps.). Palimpsestos sonoros. Reflexiones sobre la Nueva Canción Chilena (pp. 117-137). Santiago: Ceibo. 
Ponce, D. (2008). Prueba de sonido. Primeras historias del rock en Chile (1956-1984). Santiago: Ediciones B/Comisión de Publicaciones de la Sociedad Chilena del Derecho de Autor.

Rodríguez, J. (2011). La madre del hombre nuevo se llama revolución: música popular e imaginario del hombre nuevo durante la Unidad Popular en Chile. (Tesis de maestría inédita), Universidad de Chile, Chile.

Rodríguez, J. (2015). Exil, dénonciation et exotisme: la musique populaire chilienne et sa réception en Europe. Monde(s), 8(2), 141-160. Recuperado de https://www. cairn.info/revue-mondes-2015-2-page-141.htm\#

Rodríguez, J. (2016). La Nueva Canción Chilena: un ejemplo de circulación musical internacional (1968-1973). Resonancias, 20(39), 63-91. DoI: https://doi.org/10.7764/ res.2016.39.4

Rodríguez, J. (2017). El folklore como agente político: la Nueva Canción Chilena y la diplomacia musical (1970-1973). Nuevo Mundo Mundos Nuevos. DoI: https://doi. org/10.4000/nuevomundo.70611

Rolle, C. (2005). La "Nueva Canción Chilena”, el proyecto cultural popular y la campaña de gobierno de Salvador Allende. Ponencia presentada en el III Congreso de la IASPM-AL, Bogotá, Colombia. Recuperado de https://www.oocities.org/portaldemusicalatinoamericana/Rolle.pdf

Salas, F. (2003). La primavera terrestre: cartografías del rock chileno y la nueva canción chilena. Santiago: Cuarto Propio.

Schmiedecke, N. (2014a). Os primeiros festivais da Nova Canção Chilena e a invenção de um movimento musical. ArtCultura, 16(28), 23-37. Recuperado de http://www. seer.ufu.br/index.php/artcultura/article/view/30606/16660

Schmiedecke, N. (2014b). La influencia de DICAP en la Nueva Canción Chilena. En E. Karmy y M. Farías (comps.). Palimpsestos sonoros. Reflexiones sobre la Nueva Canción Chilena (pp. 201-218). Santiago: Ceibo.

Schmiedecke, N. (2015). "Não há revolução sem canções": Utopia revolucionária na Nova Canção Chilena. São Paulo: Alameda.

Schmiedecke, N. (2017). "Nuestra mejor contribución la hacemos cantando": a Nova Canção Chilena e a "questão cultural" no Chile da Unidade Popular. (Tesis de doctorado inédita), Universidade Estadual Paulista "Júlio de Mesquita Filho", Brasil.

Sepúlveda, G. (2001). Víctor Jara: hombre de teatro. Santiago: Sudamericana.

Stiles Mor, J. y Suescun Pozas, M. (2018). Introduction: Transnational pathways of empathy in the Americas. En J. Stiles Mor y M. Suescun Pozas (eds.), The art of solidarity: visual and performative politics in cold war Latin America (pp. 1-20). Austin: University of Texas Press. 
Valladares, C. y Vilches, M. (2009). Rolando Alarcón: La canción en la noche. Santiago: Quimantú.

Vila, P. (2014). Introduction. En P. Vila (ed.), The militant song movement in Latin America: Chile, Uruguay, and Argentina (pp. 1-17). Lanhan: Lexington Books.

Villaça, M. (2004). Polifonia tropical: Experimentalismo e engajamento na música popular (Brasil e Cuba, 1967-1972). São Paulo: Humanitas FFLCH-USP. 